\title{
Metallic mercury induced tremor in rabbits and mercury content of the central nervous system
}

\author{
KATSUHIRO FUKUDA \\ Department of Public Health, Hokkaido University School of Medicine, Hokkaido, Japan
}

\begin{abstract}
Fukuda, K. (1971). Brit. J. industr. Med., 28, 308-311. Metallic mercury induced tremor in rabbits and mercury content of the central nervous system. Tremor induced by metallic mercury was experimentally produced in rabbits by intermittent exposure to mercury vapour (average concentration of $4.0 \mathrm{mg} / \mathrm{m}^{3}$ for $6 \mathrm{hr} /$ day on 4 days/week for 13 successive weeks). Two of six male rabbits exposed developed fine tremor and clonus in the fore- and hind-legs after 13 weeks' exposure. Electromyographic records showed typical grouped voltages accompanying the clonus (amplitude 0.3 to $1.0 \mathrm{mV}$, duration 20 to $30 \mathrm{~ms}$, frequency 14 to 15 per second).

Activation analysis of the central nervous system showed mercury levels ranging from $0 \cdot 8$ to $3.9 \mu \mathrm{g} / \mathrm{g}$ wet tissue. The concentration in the cerebellum, the tegmentum, and the thalamus was significantly higher than in the remaining structures. The relationship between the tremor and the mercury content of the central nervous system is discussed and a positive causal relationship is suggested.
\end{abstract}

Tremor is a prominent symptom of metallic mercury poisoning (Baker, 1965; Luhan, 1968). The tremor is reversible and subsides if the patient is properly treated (Bidstrup, 1964; Kazantzis, 1965). This suggests that the tremor reflects the severity of the metallic mercury poisoning and that it may have some close relationship with the mercury content of the tissues involved. Although there have been some electromyographic studies on mercurial tremor (Isch, Rohmer, and Marx, 1950; Suzuki, Kubota, and Kogi, 1960), little is known about the relationship between experimental tremor and the mercury content of the central nervous system.

In the present preliminary study, tremor due to metallic mercury has been produced in rabbits and the relationship between the tremor and the mercury content of the central nervous system has been investigated.

Experimental methods and materials

A fairly constant concentration of mercury in air was generated by the method shown in Figure 1. Six normal male rabbits (body weight 2.5 to $3.5 \mathrm{~kg}$ ) were exposed to mercury vapour (average concentration of $4.0 \mathrm{mg} / \mathrm{m}^{3}$ for $6 \mathrm{hr} /$ day on 4 days/week for 13 successive weeks). The mercury concentration was frequently measured by a Kitagawa vapour detector. Each rabbit was observed and checked to see whether it showed tremor when supported by the angles of both mandibles in a vertical position sitting on its buttocks. At the end of the 13th week all the rabbits were examined in a shielded room by electromyography using a concentric needle electrode. The time constant was $\mathbf{0 . 0 1} \mathrm{s}$. Four of these rabbits (two with clonus and two without) were killed, and several different parts of the central nervous system were analysed for mercury by non-destructive activation analysis (Westermark and Sjöstrand, 1960). After being rinsed in saline and weighed, each specimen was sealed in a piece of polyethylene tube, and irradiated at a neutron flux of $1.8 \times 10^{14} \mathrm{n} \mathrm{cm}^{-2} \mathrm{~s}^{-1}$ for 20 minutes with standard and control specimens, and aged for 9 to 10 days. The gamma radiation from $\mathbf{H g}^{197}$ was measured by scintillation spectrometry with a sodium iodide well-type detector. The mercury content was calculated from the count rate after correction for background. 


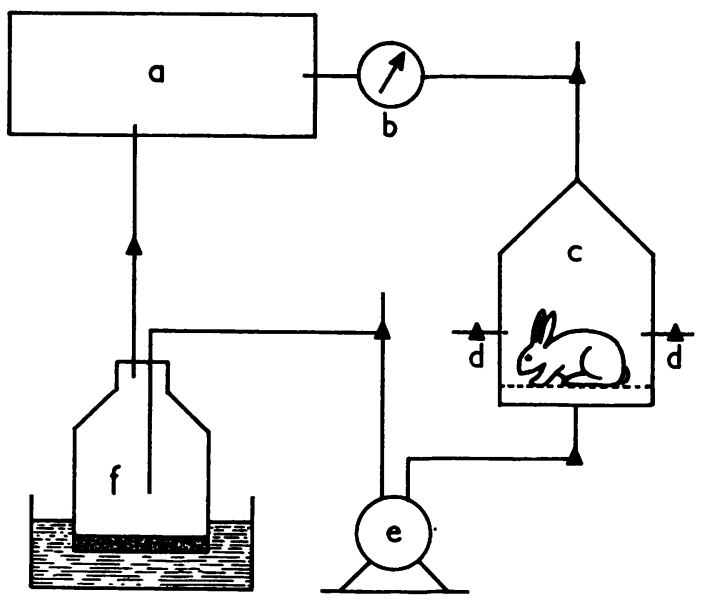

FIG. 1. Mercury vapour generator.

a. Vinyl bag (about $2 \cdot 8 \mathrm{~m}^{3}$ ).

b. Gas flow meter.

c. Air-tight stainless steel exposure chamber (about $0.5 \mathrm{~m}^{3}$ ).

d. Outlet for air sampling of intrachamber air.

e. Vacuum pump $(0 \cdot 25 \mathrm{~W})$.

f. Mercury vapourizer (a reagent bottle, metallic mercury in the bottom, bathed in water at $70^{\circ} \mathrm{C}$, controlled by a thermostat).

$\Delta$ Indicates stopcocks.

\section{Results}

None of the animals showed any tremor during the control period of two weeks before exposure. In the 11 th week of exposure the fore-legs of one rabbit occasionally showed spontaneous tremor as well as clonus when the legs were tapped. By the end of the 13th week of exposure two rabbits had occasional tremor and clonus of their fore- and hind-legs. The tremor observed was very fine and easily noticeable when the animal was set in the way described under 'Methods'. The clonus occasionally appeared spontaneously during observation but it could also be produced by tapping the legs and it tended to decrease within one minute. Furthermore, all of the six rabbits showed more exaggerated reflexes elicited by the tapping of local muscles by an operator compared with the control period.

On electromyographic examination the control rabbits showed intermittent unit discharges, which appeared continuously with almost equal inter-spike intervals on tonic contraction of the extremities, as shown in Figure 2A. The two rabbits with clonus, however, showed the typical grouped voltages presented in Figure 2B and C. The grouped voltages were 0.3 to $1.0 \mathrm{mV}$ and lasted 20 to $30 \mathrm{~ms}$ at a frequency of 14 to 15 per second.

The results of analyses for mercury, carried out on $0.17-0.41 \mathrm{~g}$ specimens, are shown in the Table. A statistical test (Scheffé, 1953) with the results shown in the Table revealed no significant difference in mercury content between the rabbits with clonus and those without (at the $10 \%$ level of significance, for the degrees of freedom $(13,14) \hat{\theta} \pm S \times D(\hat{\theta})=$ $0.086 \pm 0.84(-0.754,+0.926)$, where $\hat{\theta}$ indicates an estimated difference of the means, and $S \times D(\hat{\theta})$ indicates the confidence interval calculated by Scheffe's formula) but there was, at the $5 \%$ level, significantly more mercury in the cerebellum,
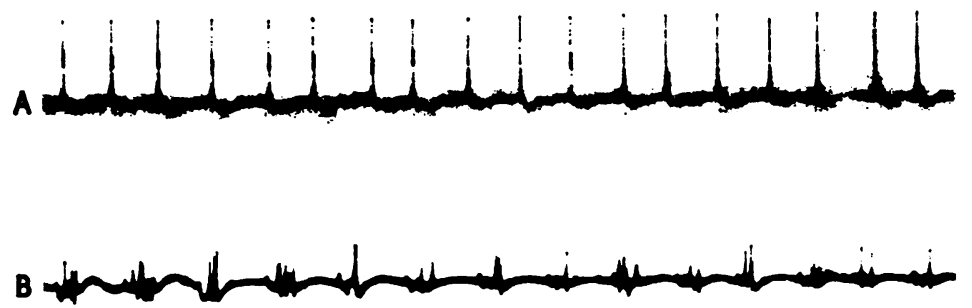

FIG. 2. Electromyograms of control rabbit (A) and those exposed (B) and with clonus (C).

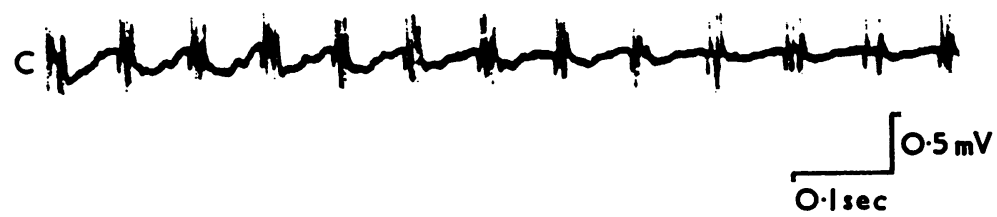


TABLE

Mercury Content' in Central Nervous System

(Each figure represents the measured value $(\mu \mathrm{g} / \mathrm{g})$ of wet tissue in each specimen.)

\begin{tabular}{|c|c|c|c|c|c|c|c|c|}
\hline & No. & Neocortex & Cerebellum & Tegmentum & Thalamus & Caudate & Pons & Spinal cord \\
\hline Rabbits with clonus & 2 & $\begin{array}{l}1 \cdot 0 \\
1 \cdot 4\end{array}$ & $\begin{array}{l}3 \cdot 1 \\
2 \cdot 0\end{array}$ & $\begin{array}{l}1 \cdot 7 \\
1 \cdot 9\end{array}$ & $\begin{array}{l}2 \cdot 3 \\
2 \cdot 8\end{array}$ & $\begin{array}{l}0 \cdot 5 \\
1 \cdot 8\end{array}$ & $\begin{array}{l}0 \cdot 9 \\
1 \cdot 2\end{array}$ & $\begin{array}{l}1 \cdot 0 \\
0 \cdot 8\end{array}$ \\
\hline $\begin{array}{l}\text { Rabbits without } \\
\text { clonus }\end{array}$ & 2 & $\begin{array}{l}1 \cdot 3 \\
1 \cdot 4\end{array}$ & $\begin{array}{l}1 \cdot 8 \\
2 \cdot 5\end{array}$ & $\stackrel{*}{*} \cdot 8$ & $\begin{array}{l}3 \cdot 9 \\
2 \cdot 8\end{array}$ & $\begin{array}{l}0.8 \\
1.0\end{array}$ & $\begin{array}{l}1 \cdot 2 \\
1 \cdot 2\end{array}$ & $\begin{array}{l}0.9 \\
1 \cdot 2\end{array}$ \\
\hline
\end{tabular}

* No specimen

tegmentum, and thalamus than in the remaining structures (degree of freedom $(13,14), \hat{\theta} \pm \mathbf{S} \times \mathbf{D}(\hat{\theta})$ $=1 \cdot 27 \pm 1 \cdot 11(+0 \cdot 16,+2 \cdot 38))$.

\section{Discussion}

Previously, Ashe et al. (1953) examined the effects of an intermittent and controlled exposure to mercury through the respiratory tract for a fairly long term on rabbits. But they did not report tremor. Beliles, Clark, and Yuile (1968) found fine tremors in the fourth week in rats repeatedly exposed to mercury vapour $\left(17 \mathrm{mg} / \mathrm{m}^{3}\right.$ for $2 \mathrm{hr} /$ day on 5 days/week for about 4.5 successive weeks) and they also found some histological changes in the central nervous system, but they did not report the mercury content in the tissues.

The present work has shown that rabbits may develop spontaneous tremor as well as clonus following a series of intermittent exposures to mercury vapour and has also suggested some causal relationship between tremor and the mercury content in the central nervous system. The tremor was associated with grouped voltages of the electromyogram, as one might expect. These voltages are known to appear in several situations and have been customarily regarded as of central origin when such peripheral factors as muscular fatigue, exposure to cold, atrophy of disused muscles, rheumatic arthritis, and myelitis can be excluded (Hori and Yoshii, 1956). Since none of these local factors was operative in the present study, the tremor observed may be of central origin and the mercury in the central nervous system may have some causal relationship with the tremor, supposing some dose-response relationship of mercury in the tissues (Passow, Rothstein, and Clarkson, 1961).

Although there were no significant differences in the mercury content of the rabbits with clonus and those without, the present study disclosed higher concentrations of mercury in the cerebellum, tegmentum, and thalamus than in the other structures. The cerebellum is a highly important extrapyramidal structure, and both the tegmentum, including the substantia nigra, and the thalamus have some functional significance in extrapyramidal motor control (Cooper, 1966). It is, therefore, possible that some functional impairment of these structures may cause, at least in part, the tremors observed.

These are only preliminary experiments, and further studies are necessary to provide fuller information for an estimation of the probable rate of appearance of the tremor under such conditions as those described here.

The author is greatly indebted to Professor T. Yokota, M.D., and to Dr. T. Yamauchi, M.D., of Hokkaido University for the electromyographic recording and for guidance; to Professor T. Morozumi and Dr. H. Ohashi for suggestions about the activation analysis; to Professor A. Okada, M.D., of Sapporo Medical College for providing the exposure chamber; to Professor S. Abe, M.D., and Professor S. Watanabe, M.D., for their help. Permission for irradiation for the activation analysis at the Institute of Atomic Energy was given by the special committee of the Science Council for common usage of the atomic pile.

\section{References}

Ashe, W. F., Largent, E. J., Dutra, F. R., Hubbard, D. M. and Blackstone, M. (1953). Behaviour of mercury in the animal organism following inhalation. Arch. industr. Hyg. $7,19$.

Baker, A. B. (1965). Clinical Neurology, 2nd ed., vol. 2, p. 990. A Hoeber-Harper International Edition, jointly published by Harper and Row, New York and Weatherhill, Tokyo.

Beliles, R. P., Clark, R. S., and Yuile, C. L. (1968). The effects of exposure to mercury vapor on behaviour of rats. Toxicol. appl. Pharmacol., 12, 15-21.

Bidstrup, P. L. (1964). Toxicology of Mercury and its Compounds, p. 58. Elsevier, Amsterdam.

Cooper, I. S. (1966). A cerebellar mechanism in resting tremor. Neurology, (Minneap.), 16, 1003-1015.

Hori, H., and Yoshii, N. (1956). Today's Electromyography, p. 76. Nagai Shoten, Osaka.

Isch, F., Rohmer, F., and Marx, C. (1950). Etude électromyographique d'un cas de tremblement mercuriel. Rev. neurol., 82, 578.

Kazantzis, G. (1965). Chronic mercury poisoning-clinical aspects. Ann. occup. Hyg., 8, 65-71. 
Luhan, J. A. (1968). Neurology: A Concise Clinical Textbook, p. 19. Williams and Wilkins, Baltimore.

Passow, H., Rothstein, A., and Clarkson, T. W. (1961). The general pharmacology of the heavy metals. Pharmacol. Rev., 13, 185-224.
Scheffé, H. (1953). A method for judging all contrasts in the analysis of variance. Biometrika, 40, 87-104.

Suzuki, T., Kubota, K., and Kogi, K. (1960). Electromyographical study of workers exposed to mercury vapor. Jap. J. industr. Hlth, 2 (1), 21.

Westermark, T., and Sjöstrand, B. (1960). Activation analysis of mercury. Int.J. appl. Radiat., 9, 1.

Received for publication November 10, 1970.

\section{The April (1971) Issue}

Rheumatism in industry: a review J. A. D. ANDERSON

Oil dermatitis: an enquiry into its prognosis $M$. L. JoHNSON AND H. T. H. WILSON

Sickness absence levels and personality inventory scores R. W. HOWELL AND SIDNEY CROWN

An elaboration of small opacity types ( $p, m$, and $n$ ) in simple pneumoconiosis D. C. Lindars

Studies on the aetiology of byssinosis Geoffrey Taylor, A. A. E. Massoud, and F. Lucas

Pulmonary function at rest and during exercise following bagassosis G. J. Miller, C. E. D. Hearn, AND R. H. T. EDWARDS

Peak flow rate in relation to forced expiratory volume in hemp workers E. ZUSKIN AND F. VALIC

Physiological changes during electrical asphyxiation L. S. LEVY

Evaluation of exposure to phenol: absorption of phenol vapour in the lungs and through the skin and excretion of phenol in urine Jerzy K. PIOTROwSKI

Effects of chrysotile and acid-treated chrysotile on macrophage cultures E. G. BECK, P. F. HoLT, AND E. T. Nasrallah

Inhibition of the absorption of paraquat from the gastrointestinal tract by adsorbents D. G. CLARK

Balance between intake and output of lead in normal individuals JENNIFER A. THOMPSON

Correlation between some parameters of lead absorption and lead intoxication H. A. WALDRON

Notes and miscellanea

Occupational health and safety in Great Britain 1969 KenNeth P. DunCAN

Excretion kinetics of urinary metabolites in a patient addicted to trichloroethylene MASAYUKI IKEDA, Hatsue Ohtsuji, Hitoshi Kawai, and Masaichi KuniYoshi

Book reviews

A number of copies are still available and may be obtained from the Publishing Manager, British Medical Association, Tavistock Square, London WC1H 9JR price $£ 1 \cdot 25(£ 1 \cdot 5$ in countries overseas; U.S.A. $\$ 3 \cdot 60$ ). 